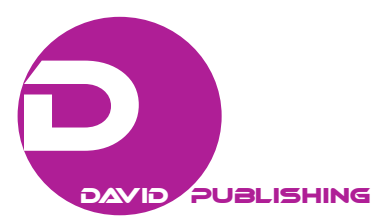

\title{
Main Regulations of CAPM Model and Its Modern Modification
}

\author{
Lamara Qoqiauri \\ Institute of Economic Researches, Tbilisi, Georgia \\ Nino Qoqiauri \\ Qutaisi University, Qutaisi, Georgia
}

\begin{abstract}
The article gives readers the main regulations of elaboration of capital actives evaluating model (CAPM) theory, topics of its practical usage, common ways of definition of investments (securities) optimal portfolio and on the basis of CAPM theory it is discussed evaluating methods of investing business, and it is highlighted two criteria of portfolio chosen by an investor-profit and risk. Besides, it is discussed modern modification of the mentioned model on the point of time horizon, a problem of time factor measurement while evaluating risk and profit, also evaluation of investing effectivity by using sharp coefficient. The work presents and evaluates possible income of securities and possibilities of risks in a modern way, which is characteristic only for CAPM model and it is considered to be its positive side.
\end{abstract}

Keywords: securities, risk, income, CAPM model, stock market, bond market, optimal portfolio, investments, market, sharp coefficient

\section{Introduction}

Activities at the exchange market always include particular risks. Investors, purchasing securities, are to take decisions under the conditions of uncertainty, when it is impossible to predict future results with $100 \%$ confidence, as a result of which each decision is exposed to particular risks. The risks foresee probabilities of uncertain result, when investor fails to receive expected results. When taking decision, it is necessary not only to foresee expected effectiveness from investment of sources into particular securities, but also to evaluate level of the risk of investment.

When considering risk as probable non-performance of expected outcomes, it shall be considered that the event may happen or not. Depending on the exposure to the risk, two extreme positions of investors may be allocated. The first type represents the investors, entirely ignoring risk and taking decision based only on the indicators of future rate of return. As a result of favourable set out circumstances, we will be able to make high profit. However, an investor may suffer serious loss as well, if the situation is not in his favour. Second type may include the investors having panic fair of risk and preferring to reject investments into the securities and potential future incomes, as receiving positive result is not fully guaranteed. Under such condition, an investor is secured against risks and possible losses. However, he rejects future possible profit as well; i.e., investor suffers loss in the form of lost profit. As always, the truth is somewhere in the middle: Investor shall have fear

Lamara Qoqiauri, doctor of Economics, professor, leading scientist-collaborator of the Institute of Economic Researches, Tbilisi, Georgia.

Nino Qoqiauri, doctoral student, Faculty of Economics and Business, Qutaisi University, Tbilisi, Georgia.

Correspondence concerning this article should be addressed to Lamara Qoqiauri, M. Gakhokidze st. 159, Tbilisi 0163, Georgia. 
for risk and adopt it within reasonable limits for particular investments, developing the system of risks management. Due to this, following is necessary for taking decision on investments:

- To determine expected future rate of return from purchasing particular securities;

- To evaluate possible risks, characterising particular type of shares;

- To compare risk and rate of return and evaluate degree of riskiness of investments.

In general, price-creating theory of financial sources tries to find the answer to the question - what kind of influence will investors' joint action make (who try to reach maximum possible income in conditions of given level of risk) on relations between possible income and risk? In scientific sphere this question is called "theory of capitals risk". It tries to define balanced price interrelation which should be existed between predicted income and risk. In other words, with the help of capital market theory it gets clear-how much predicted income of financial resources increase in case of increasing its risk by one unit.

It was possible to solve the above mentioned hard topics by means of financial price-creating model (Capital Asset Pricing Model-CAPM).

A lot of scholars dedicated their works to study the mentioned topics. We also had to know and analyze theoretical and practical sides of the mentioned problems while studying investments and securities market, to publish scientific articles and monographs (Qoqiauri, 2010; 2013).

The aim of the work is not only a short review of CAPM model, but its modification on the point of time horizon of investments. Apparently we could not neglect the topic of profit and risk measurement, measurement of time factor while evaluating risk and profit, also evaluation of investing effectivity by using sharp coefficient.

\section{Main Part}

\section{Main Regulations of CAPM Model}

CAPM model was offered separately by three American economists-W. Sharpe, J. Lintner and J. Mossin. It is connected to capital actives evaluating model, the so-called CAPM (Capital Asset Pricing Model) (Sharpe, Alexander, \& Beili, 1995). Sharpe's, Lintner's and Mossin's works were dedicated to one and the same topic: "Let us assume that every investor has the same information and evaluates profit and risk of separate shares in the same way. Let us also assume that because of their obsession to risk they create their optional portfolio of shares according to Markovits' theory. How will prices be fixed on stock market in this case?"

In this way we can discuss CAPM as macroeconomic generalization of Markovits' theory. The main result of CAPM became to fix the correlation between active profit and risk for a market balance. While choosing optimal portfolio, an investor should consider not the "whole" risk, which is connected to active (risk after Markovits), but only the part that is called systematic or non-diversified risk. This part of active risk is close to common risk of the whole market and in quantity it is "Beta" coefficient, brought in by Sharpe in one-factor model, which is very important. The other part of risk (the so-called non-systematic or diversified risk) is removed by choosing (optimal) portfolio. Relation between profit and risk is of rectilineal character nowadays. CAPM remains the most important and modern theory. All practical text-books in financial management sphere rely only on it, in the part of choosing long-term investment strategy.

One more cycle of researches is connected to investment theory and financial management theory in the sphere of corporate market theory. This theory is dedicated to "adequacy" problem of market prices of financial actives. The topic shows how well market prices reflect "true" value of financial actives; the investor, who 
finds out that a market systematically evaluates an active more or less, will be able to get profit for a long time and practically without any risk. Hypothesis of effectivity proves that it is impossible. It means that market prices in a whole reflect almost all the information accessible for investors. In this case fluctuation of market prices may be purely accidental. Not a single investor can predict future prices of a market.

As we mentioned above, evaluating model (CAPM) of financial actives profit defines this interrelation which is elaborated by J. Lintner, J. Mossini, and W. Sharpe. CAPM model is constructed on the following possibilities: existence of ideal markets of capital, nonexistence of taxes, operating expenses, etc. According to the model required income for any kind of risky actives presents a function of three variables: non-risky profit; middle profit on securities market; and fluctuation index of profit of the given fund active (financial acting towards the existed profit entirely on the market).

According to CAPM relations between risk and profit graphically can be shown by means of capital rising line (Figure 1).

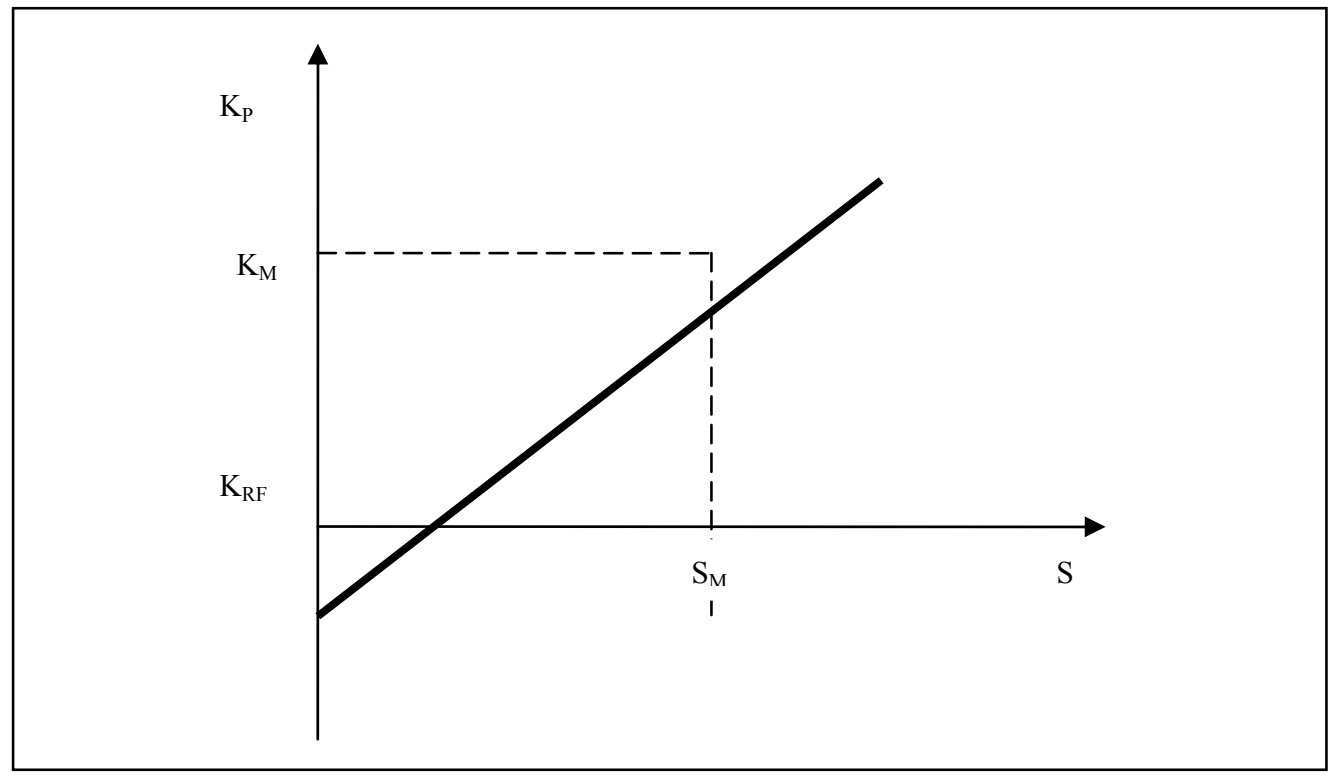

Figure 1. Capital rising straight. Source: Qoqiauri (2010).

In securities the profit got from investments is directly proportional to the risk, which is accepted by an investor because of desirable profit. Connection between risk level and profit standard is equal to profit standard of non-risky investments plus premium for risk according to the given investments.

An investor chooses his optimal portfolio from those numerous portfolios each of which:

- Supports maximum predicted profit for some level of risk;

- Supports minimum risk for some meaning of predicted profit.

The totalities of those portfolios which satisfy these two conditions are called effective multiplicity. Herewith, those portfolios which are on the edge of this multiplicity are especially important. In this model by comparing arithmetic mean (predicted) of securities and standard bending of profit is explained interrelation which should be between predicted profit a of each securities and risk. These possibilities characteristic only for CAPM model may be formed in this way:

(1) Investors evaluate portfolios and compare probable profit and dispersion (standard bending) with each other. For each portfolio during one holding period, i.e., their attitudes towards a portfolio investments, an 
investor defines only by two parameters — predicted profit and dispersion (standard bending);

(2) Investors who have a possibility of choosing two identical portfolios with the same profit (one and the same risk level), always choose the portfolio which supports its high profit;

(3) Every investor tries to prevent from extra risk, i.e., from two identical portfolios with the same profit they always choose the portfolio with lower level risk;

(4) Each financial means can be divided into indefinite and unlimited parts and an investor can purchase any piece of his desirable shares or bonds;

(5) There are some securities which have no risk. Investing money in these financial sources is not connected to any risk which brings non-risky profit to an investor. Moreover, an investor may lend out any amount of his free money or borrow his desirable sum of money. Percentage rate is the same for all investors;

(6) There is no obstacle for investors to carry out buying and selling financial resources: Taxes and commissions are not considered. It is common that investors don't pay for diversification;

(7) Every investor has homogeneous expectation towards the duration of holding period, also towards profit of financial sources. It means that investors create and look through their portfolios after one and the same time. Besides, every investor agrees to evaluate division of accidental sizes of securities or portfolio profit;

(8) There is no non-definition towards predicted level of inflation;

(9) All kinds of information about functioning of financial markets are absolutely accessible for any investor;

(10) Capital markets are balanced, i.e., all investment decisions are accepted and no arrangement will be made without profit of additional information.

\section{Measurement of Risk and Rate of Return}

Incentive for investment of cash resources into the shares represents aspiration to get income from increasing rate of value and dividends, which may be paid to the investor during the period of holding the shares. Annual income from investments into the shares $(r)$ may be determined in the following form:

$$
r=\frac{d+\left(P_{1}-P_{0}\right)}{P_{0}} \cdot 100
$$

where $d$ means dividends, $P_{0}$ and $P_{1}$-market prices of shares at the time of buying $\left(P_{0}\right)$ and at the time of selling $\left(P_{1}\right)$.

If considering investment process for long-term period, the shares, as a rule increase in prices. For example, during the period from 1926 through 2007, average annual profitableness of US shares, included in S\&P-500 index, was $14.4 \%$, and rate of income of shares of small companies made approximate profit in the amount of $19.6 \%$ to their holders. However, there are ups, when cost of shares was rising for 50 or more percent, and downs of marketable value, especially during the Great Depression and modern global economic crisis.

The crisis taking place in USA in 2007 resulted in sharp decreasing of citation of shares. This is clearly observed through the dynamics of exchange indexes, as at the developed, so-developing stock exchanged. The most famous American industrial Dow-Jones index decreased from its maximum achieved in 2007 in the amount of 14,164 points, to 6,547 points by March 2009; i.e., the decrease made $54 \%$. Volatility of securities is significantly higher at the developing markets.

RTS index increased almost 25 times from the moment of calculation, when its value was 100, until July 2008 ; i.e., average annual rate of growth, calculated as average compound value, amounted more than $28 \%$. However, global financial crisis gave rise to the sharp fall of Russian stock exchange. Within several months 
RTS index fell by 498 points; i.e., almost five-time from its maximum value. By November 2011, index played half of its fail; however, several years were required for its full recovery.

Thus, shares rise in price in long-term historic cut shares increase in price, which is related with the general growth of economy. However, increase of marketable value of shares is provided nonuniformly; ups are followed by downs. Herewith, volatility of shares differs. On the conditional example (Figure 2) it can be seen that shares of the Company A and Company B for the observed period increased in price and made similar income to their holders. However, in different times there was decrease in marketable value. If investor buys share on the date $t_{1}$, and then he is in need of cash resources, and he sells them on the date $t_{2}$, he suffers loss, as shares decreased in price. Herewith, loss on the share B was higher, than that of the share A. It can be clearly seen on Figure 2 that volatility of marketable value of the Share B is higher compared to the Share A. Procurement of the shares at the moment of stock price decline and their sale during maximum increase, may give rise to great profit. However, it is probable that securities are sold under low prices, and in such case, investor suffers financial loss. Taking into account the fact that volatility of prices on the Share B is higher than that with the Share A, we may assume that Share B is exposed to higher risk. In this regards, it is important to evaluate risk level and give it quantitative evaluation.

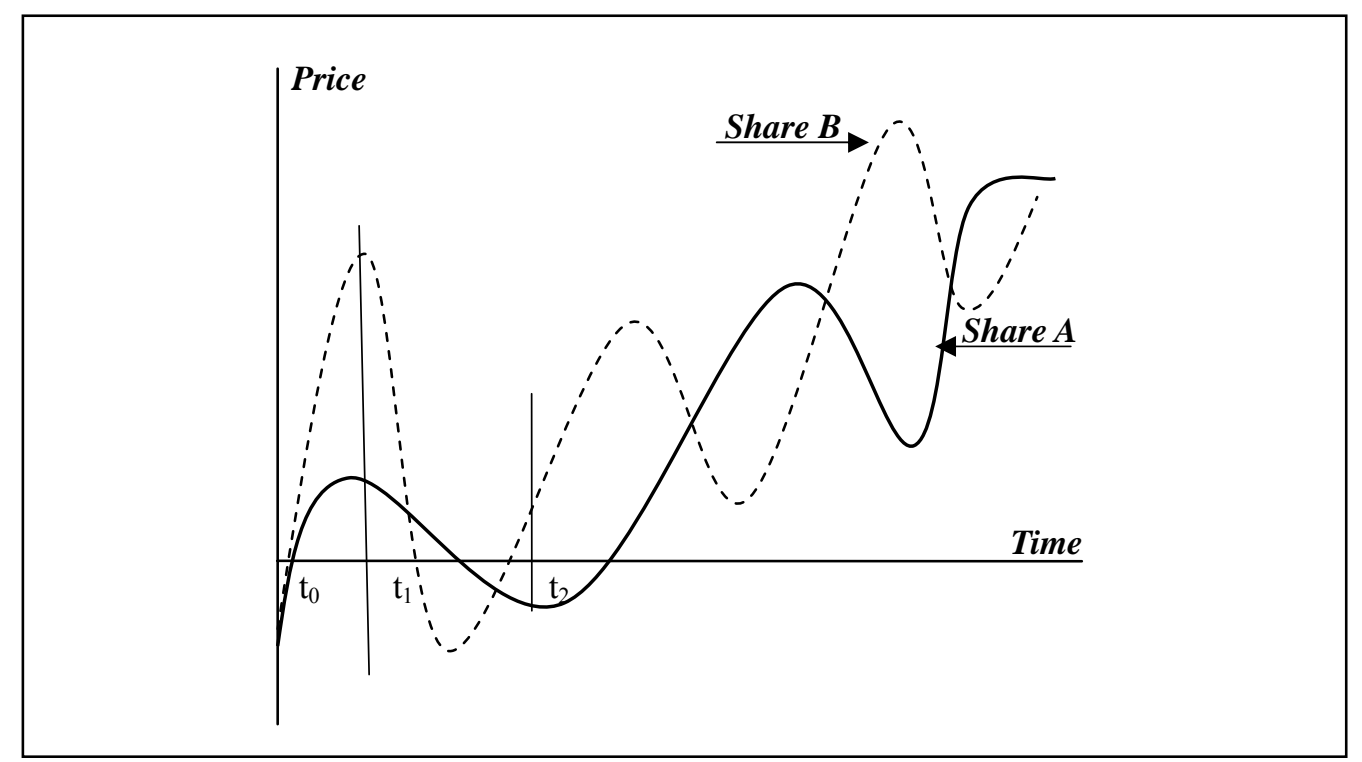

Figure 2. Dynamics of marketable value of shares of the Company A and Company B. Source: Sharpe (1970).

Risks related with the investments into the securities are characterised with probable values of expected outcome. In regards with the fact that taking decision is provided under the conditions of uncertainty, it is hard to predict particular level of rate return, as prices at the stock exchange are continuously changed. For evaluation of the investment risk, they use variation indicators, characterising the level of volatility of profitableness of shares from the average value based on the statistic data for profitableness of such financial assets during previous years. For measurement of the level of volatility they calculate dispersion of random value $(x)$ with the following formula:

$$
\sigma_{x}^{2}=\sum_{i=1}^{n} \frac{\left(x_{i}-\bar{x}\right)^{2}}{n-1}
$$


where $x_{i}$ is value of variable $x$ at the moment of the time $i ; x$-mean value for variable $x$; $n$-number of observations in the sample. Based on the indicator of dispersion they calculate standard declining, variation ratio, and other indicators, characterising volatility of financial instrument and serving basis for taking investment decisions.

\section{Evaluation of Risk in CAPM Model}

The essence of the risk for different types of investments are determined in the fundamental work of W. Sharpe (Sharpe, 1970), giving methodology of its evaluation compared with the rate of return. In the investment theory, risk of financial instrument is evaluated with the volatility level, and expected return - as mathematic expectation.

In the classic financial theory, relation between risk and rate of return is described with lineal function, giving most clear demonstration of CAPM model (Capital Asset Pricing Model). In the said model, rate of return of financial instrument represents function from profitableness of risk-free investments and premium for investment risk.

Expected level of profitableness from investments in $i$ assets is determined based on the following formula:

$$
r_{i}=r_{f}+\beta_{i}\left(r_{m}-r_{f}\right)
$$

where $r_{f}$ is risk-free rate of return; $r_{m}$-level of market profitableness; $\beta_{i}-\beta$ ratio per $I$ asset, characterising risk of the said asset.

If risk-free rate of return, which may be taken return on the US treasury bills, amounts to $5 \%$, level of market yield $\left(r_{m}\right)$ equals to $15 \%$, and $\beta$ ratio of the company $\mathrm{A}$ is at the level of 1.3 , requested level of the rate of return from the investments into the shares of the said company shall be determined in the following form:

$$
r \mathrm{~A}=5+1.3(15-5)=18 \% .
$$

Graphical model of the capital market is presented in Figure 3.

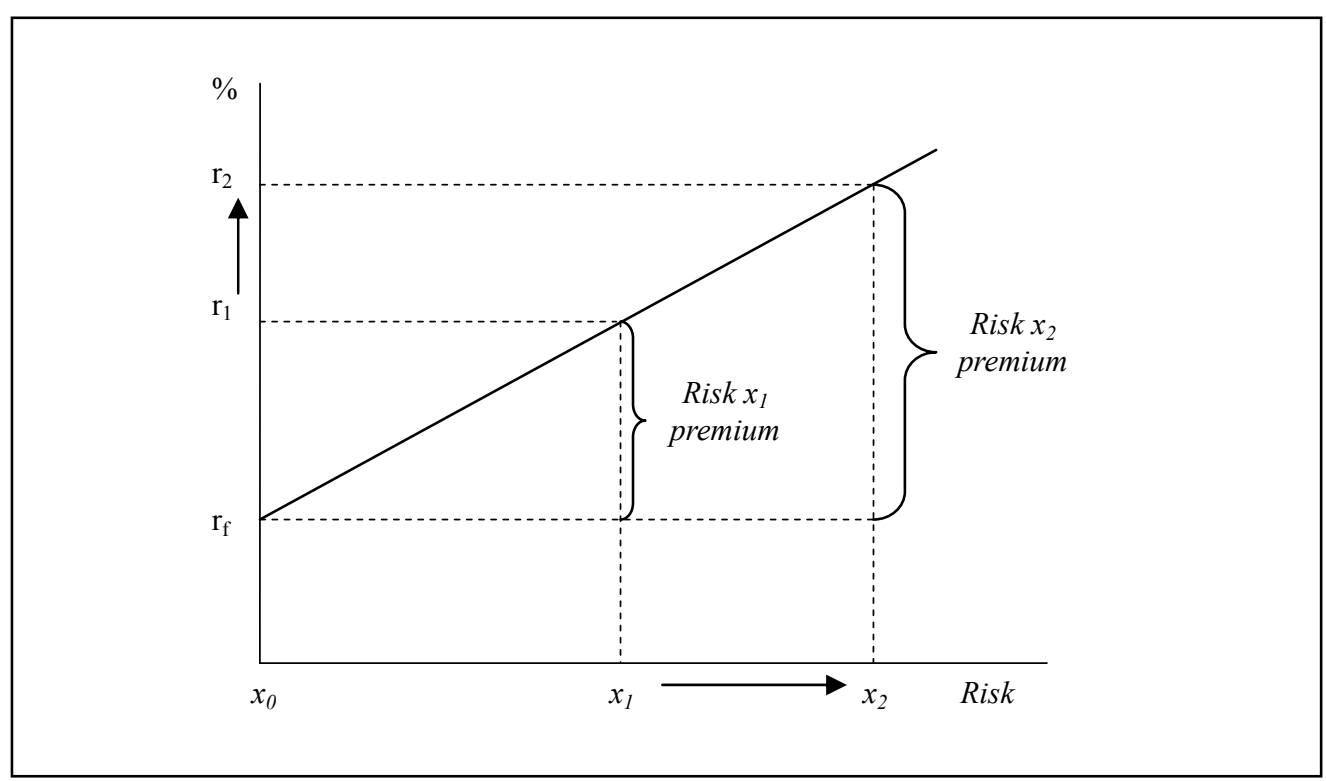

Figure 3. CAPM Model. Source: Sharpe (1970).

Reviewing dependence of risk and rate of return in CAPM model is carried out in the same flatness with the coordinates "Risk-Rate of Return". Said model reflects fundamental method of approach to the evaluation 
of risk and rate of return: The higher is the risk, the higher rate of return the investor shall receive. Due to the fact that relation of risk and rate of return is expressed in lineal function, rate of return may be increased, only by taking additional risk. If investor desires to earn income $r_{2}$ along with the income $r_{1}$, he shall invest in the asset with risk $x_{2}$ instead of investment into the asset with risk $x_{1}$, exposed to higher risk. If investor desires mitigation of risk, he shall agree with lower rate of return.

Illustration of relation of risk and rate of return is given in Table 1 below, where securities are ranged per the risk level.

Table 1

Risk and Rate of Return of Securities at US Stock Exchange for 1928-2008

\begin{tabular}{llll}
\hline Securities & $\begin{array}{l}\text { Annual average rate of } \\
\text { return (\%) }\end{array}$ & Risk premium (\%) & Risk (standard decline) (\%) \\
\hline Treasury bills & 3.74 & - & 3.02 \\
Long-term state bonds & 5.45 & 1.71 & 7.61 \\
Shares & 10.18 & 6.44 & 19.53 \\
\hline
\end{tabular}

Source: www.federalreserve.gov.

They take short-term bonds of US government in the form of risk-free financial instrument, as investors consider default risk on such securities equal to 0 , and rate of return is guaranteed in the event if the asset is maintained to the maturity date. Long-term state bonds are more profitable; however, they are exposed to high risk, which is characterized with the higher value of standard declining. This is conditioned by the fact that when purchasing such bonds with the term of one year, investor may have as return, so-loss, due to the volatility of prices. Shares appeared to be more profitable financial instruments making average annual income to the investors in the amount of $10.18 \%$ during observable period. However, this financial instrument is exposed to the highest risk, reflecting indicator of standard deviation.

Figure 4 shows chart of normal distribution of the annual rate of return per shares and bods during the period from 1928 through 2008.

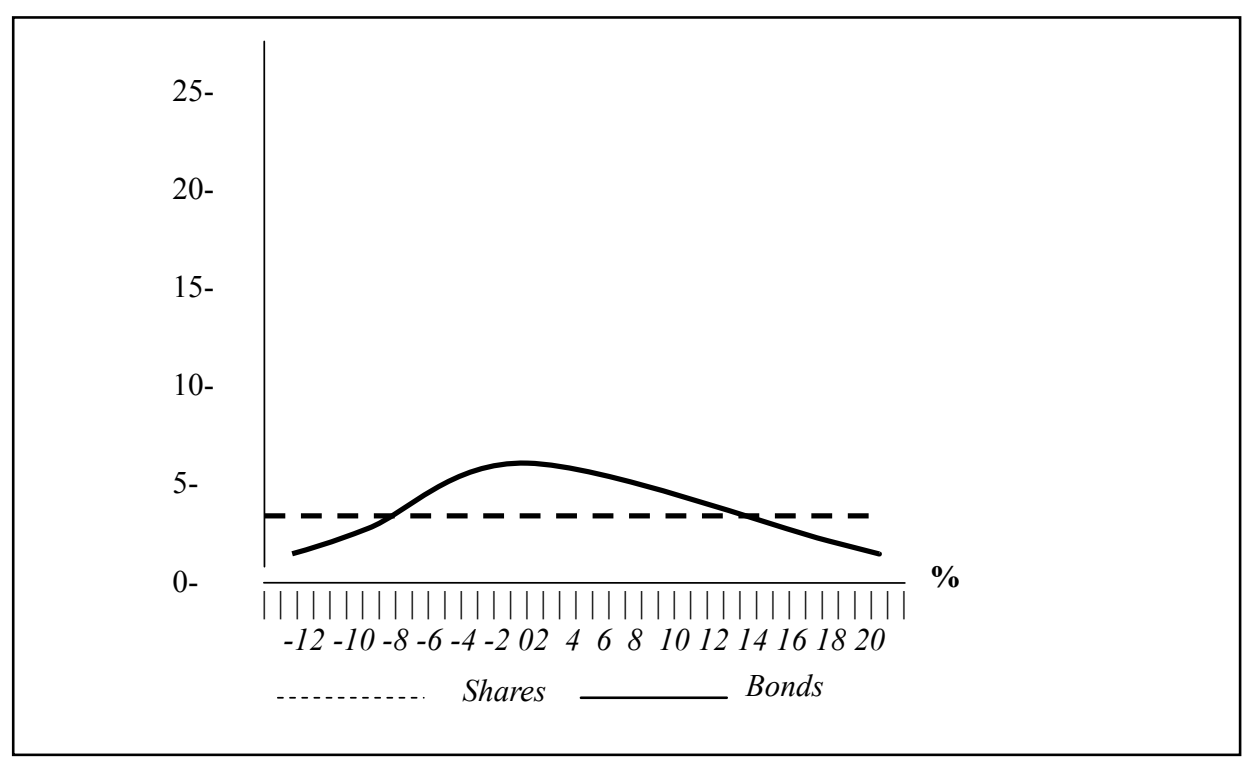

Figure 4. Chart of normal distribution of annual rate of return per shares and bonds at US stock exchange during the period from 1928 through 2008. 
Gaussian gently sloping curve per shares characterizes higher distribution of indicators of the rate of return from average value and the higher standard deviation. Steeper curve on bonds characterises high concentration of indicators of annual rate of return to its average value and relatively lower risk.

Given data confirm the logic of relation between risk and rate of return and conforms to the traditional opinion allocating financial instrument to the low-income and low-risk ones, or on the contrary, to the instruments of higher opportunities for earning income, but being exposed to higher risks. In the classical theory of investment, shares are considered as risky investments, which may be highly profitable, or essentially unprofitable. The bonds are deemed to be objects of investments less exposed to risks. This is traditional point of view about short term investment of resources.

\section{Considering Time Factor in Course of Evaluation of Risk and Rate of Return}

Some researchers argue that there is relationship between ratio of asset risk and rate of return and time horizon of investment. For example, R. Ibbotson and P. Chen (Ibbotson \& Chen, 2002) showed that for continuous terms investments of shares represent more favourable financial instruments than bonds, as risks in continuous period are being novelised. R. Gibson (Gibson, 2000), and D. Robertson and S. Wright (Robertson \& Wright, 1998) have same opinion. Due to this, in the event of investment for long-term period, determination of risk may be related with the influence of another factor-length of the period of investment itself.

CAPM is based on the following assumptions:

- Investors behave as rationally and avoid risk;

- Investors may credit and be credited per risk-free rates;

- Investors similarly evaluate volatility of rate of return of financial instruments;

- Securities are infinitely divisible;

- Investors may invest unlimited sources into any set of financial instruments without essential change in their prices and rates of return;

- Investors place cash resourced on similar time horizon and have approximately similar opinions about risk behaviour.

If excluding one of the given assumptions, related with the similar period of investment, we may assume that in case of investment for different terms, time factor is able to influence significantly upon the transformation of relation of the risk and rate of return of different financial instruments and to take different investment decisions. This gives rise to the necessity for evaluation of the influence of time horizon upon relation of the risk and rate of return of different financial instruments.

Researching dependence of risk and rate of return of financial instruments with the duration of the investment requires foreseeing as long time period as possible. Due to this, for analysing they selected US stock exchange, having extremely long development history. This allows operation of data of significant time period-from 1928 through 2008.

Analyse was carried out based on the following data:

- Stock market is analysed based on the industrial Dow-Jones index;

- Bond market is analysed based on the data of 10-year treasury bonds;

- Rate of return per three-month treasury bills was used as risk-free rate.

Researched period is comprised of 80 years. During this time horizon, they foresaw changes in the indicators of average annual yield of return and volatility of these financial instruments on different time 
intervals: $1,10,20$, and 30 years. Hence, the intervals were being formed as sliding value with a shift of one year. This resulted in creation of 80 single-year periods, 70 ten-year periods, 60 twenty-year periods, 50 thirty-year periods.

In case of the terms of investment of more than one year, indicators of average annual yield per shares and bonds were calculated by using the method of complex interests, as root of $i$ degree from the rate of return, received through investment, in which $I$ years were calculated according to the following formula:

$$
r_{T}=\left(\sqrt[i]{\prod_{i=1}^{T}\left(1+r_{i}\right)-1}\right) \cdot 100,
$$

where $r_{T}$ is average annual yield.

Indicators of risk and rate of return for short-term investment periods, equalling to one year, are presented in Table 2.

Table 2

Indicators of Average Annual Yield and Risks of Investments Into the State Bonds and Shares at the US Market During the Period 1928-2008

\begin{tabular}{lllll}
\hline \multirow{2}{*}{ Type of securities } & \multicolumn{4}{l}{ Annual rate of return $(\%)$} \\
\cline { 2 - 5 } & Min & Max & Average & 3.02 \\
\hline Three-month treasury bills & 0.03 & 14.30 & 3.74 & 7.61 \\
10-year state bonds & -8.25 & 32.81 & 5.45 & 19.53 \\
Shares & -46.57 & 67.84 & 10.18 & \\
\hline
\end{tabular}

Source: Ibbotson \& Chen (2002).

As it can be seen in the presented data, in case of investment for the term of one year, average annual yield exceeded return rate of state bonds for more than twice. However, spread of the rate of return per this instrument amounts from -46.57 to $67.84 \%$, characterizing higher market risk of shares, standard decline on which is $19.53 \%$. Variation of the rate of return of bonds is significantly lower. Based on this, in the classical theory of investment, shares are considered as more risky financial instruments compared to the bonds, as shares can bring as high profit, so significant loss to the investors. However, this statement is fair only in case of the reviewed term of investment, and particularly — one year.

In case of extending terms of holding securities, spread of the rate of return is significantly reduced, which is reflected in the reduction of the indicator of standard decline, which can be observed in the Table 3 below.

As it can be seen from the data in Table 3, in case of extending terms of investment spread of the rate of return of reviewed financial instruments is significantly reduced, which is shown in Figure 5. However, the spreads of return per shares are reduced in significantly higher rates than per bonds. Similar conclusions were made by other researchers as well, touching upon the said problem, for example F. Nardari, and J. T. Scruggs (Nardari \& Scruggs, 2005). It may be noted that under the extended periods of investments, it becomes impossible for the shares to make at least small negative return.

Particular paradox may be noted. For example, according to the classic opinions, shares represent more risky financial instruments. Hence they shall have large return. This is reliably showed in the works of modern researchers, for example, in the articles A. Barberis, M. Huang, and T. Santos (Barberis, Huang, \& Santos, 1999). Presented charts give clear image of the fact that such situation is fair, though for short-term periods of 
investments. Under long term periods, maintenance of the share position is exposed to lower risk and at the same time they are more profitable. Due to this, we may speak about existence of strong influence of investment terms on the correlation of risk and return. Extending time horizon of investment gives rise to the decreasing of volatility, which is characterised with lower indicators of standard deviation per the financial instruments under review. Herewith, volatility of shares is reduced in much higher rates than per bonds (Figure 6).

As a result of extending investment terms, Gaussian curve becomes more concentrated towards central axis, thus giving rise to the reduction of the spread of indicators of maximum and minimum returns. Herewith, flatness of the spread of probabilities per shares is increased much faster than per bonds, and it overcomes bond at the larger time horizon.

Table 3

Indicators of Average Annual Yield and Risks of Investments Into the State Bonds and Shares at US Market on Different Time Horizon During the Period From 1928 Until 2008 (\%)

\begin{tabular}{|c|c|c|c|c|}
\hline Indicators & 80 one-year periods & 70 ten-year periods & 60 twenty-year periods & 50 thirty-year periods \\
\hline \multicolumn{5}{|l|}{ Bonds } \\
\hline Rate of return max. & 32.81 & 13.67 & 10.66 & 8.95 \\
\hline Rate of return min. & -8.25 & 0.78 & 1.60 & 1.90 \\
\hline Rate of return, average & 5.45 & 5.17 & 5.13 & 4.92 \\
\hline $\operatorname{Risk}(\sigma)$ & 7.61 & 3.30 & 3.02 & 2.48 \\
\hline \multicolumn{5}{|l|}{ Shares } \\
\hline Rate of return max. & 67.84 & 18.27 & 17.36 & 13.32 \\
\hline Rate of return min. & -46.57 & -1.20 & 2.58 & 7.56 \\
\hline Rate of return, average & 10.18 & 10.54 & 10.79 & 10.37 \\
\hline Risk $(\sigma)$ & 19.53 & 5.20 & 3.45 & 1.59 \\
\hline
\end{tabular}

Source: Ibbotson \& Chen (2002).

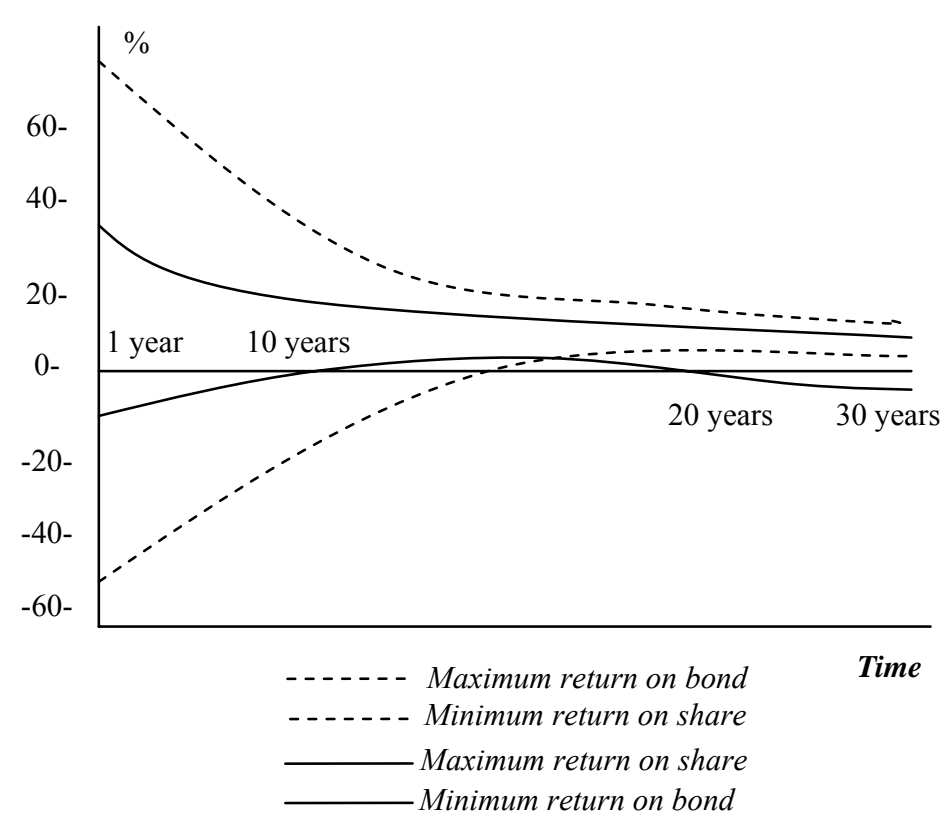

Figure 5. Maximum and nominal rates of return per shares and bonds at US exchange market, depending on the extended investments. Source: Nardari \& Scruggs (2005). 


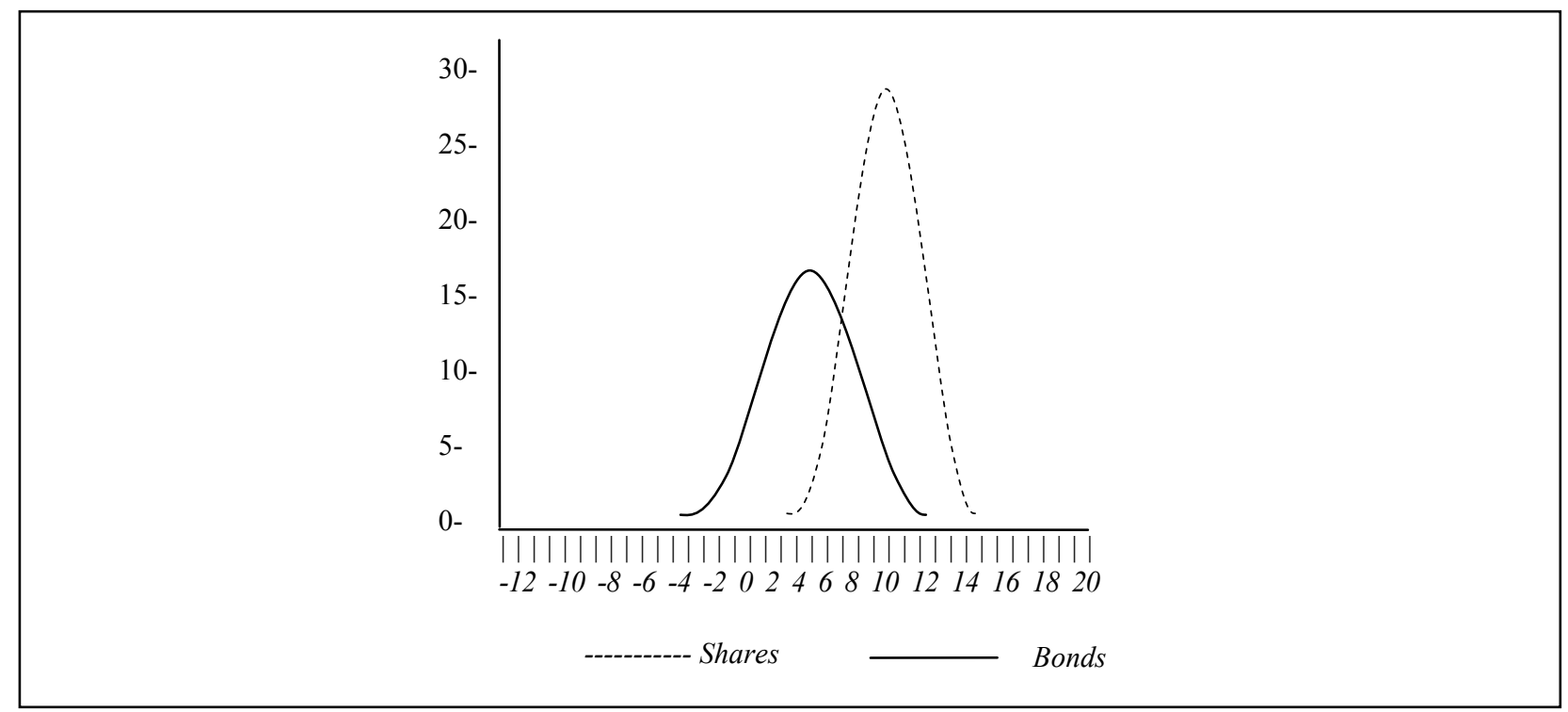

Figure 6. Chart of normal distribution of average annual return on shares and bonds at US exchange market under the investments with the term of 30 years. Source: Barberis, Huang, \& Santos (1999).

\section{Impact of Time Horizon of Investment on SML}

In the traditional system, coordinate tilt angle of Security Market Line (SML) is changed depending on the relation of investors to risk. Under the favourable forecast of economic development and optimistic evaluation future financial market, the tilt angle of Security Market Line is decreased. Under the conditions of good market conjuncture, investors give their consent for investing their sources into the securities with the similar risk level, approving less risk premium. In case of optimistic forecast, the investor assumes that probability of development of events according to unfavourable scenario is being decreased. Due to this, he/she requests fewer premiums in the form of compensation for the risk level.

In the event of increasing investors' unwillingness for risk, tilt angle of the Security Market Line is increased. This situation is occurred in case of prevailing pessimistic prognosis at the market and investors request larger premium for risk under the preset risk level. Figure 7 shows changes in SML state in relation with the primary state, in case of increasing investors' unwillingness for risk.

In case of including time factor into the model, we may expect tilt angle of Security Market Line to change depending on the investment term, as risk and yield indicators are changed with different degrees of intensity. Based on the data on annual average yield and standard decline in shares presented in Table 3, Figure 8 shows changing Security Market Line, depending of the time horizon of investments.

Figure 8 shows indicators of standard decline for different terms of investment. Point A shows standard decline under one-year term of investment, point B - under 10-year term, point C - under 20-year term, Point $\mathrm{D}$ - under 30-year term. As it can be seen, indicators of risk are quite significantly reduced in case of increasing investment terms, and indicators of average annual yield factually maintain unchanged level. Thus, by including time horizon factor into the model we may achieve preset yield under lower risk in case of development of investment strategy.

Great rate of return under the lower risk. Foreseeing time factor essentially influences upon selection of the investment object. Traditionally the bonds are considered to be less risky financial instruments than 
shares. Due to this, conservative investors are recommended to acquire bonds, as volatility of this financial instrument is much less. Shares, as the objects of investment, are recommended for aggressive investors, who are ready to take risk and reconcile with the possible loss. This definition of riskiness of financial instruments is quite fair in relation with the short-term investments. Foreseeing time factor in the investment strategy may give fundamental change to the understanding of risk and return of these financial instruments.

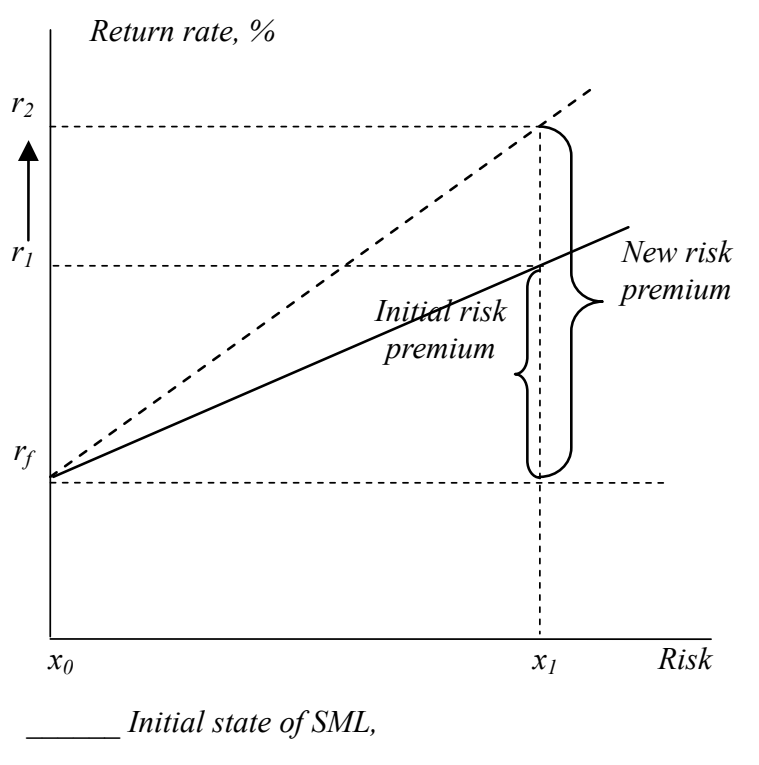

- - - - - - SML in case of increasing pessimistic expectations

Figure 7. Changing state of Security Market Line under the conditions of increasing investors' unwillingness for risk. Source: Qoqiauri (2010).

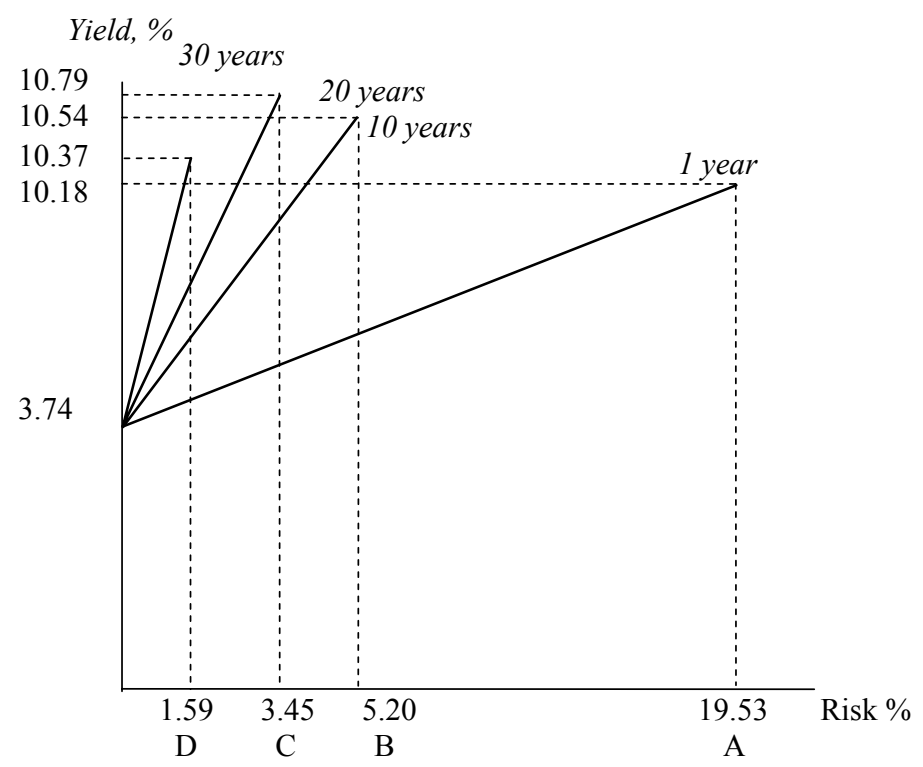

Figure 8. State of Security Market Line under different time horizons of investment. Source: Sortino \& Van Deer (1991). 
Let us consider how the indicators of risk and return of shares and bonds with the extended investment periods are being changed. Chart of standard deviation of yield per shares and bonds (Figure 9) prove the fact that standard deviation of yield on shares under the extended terms of investment is decreased in much faster rates than it happens with the bonds. For example, increasing of investment period from one year to 30 years gives rise to the decrease of standard deviation of yield per shares 12 times, while in case of bonds there is three-times decrease. This speaks of the fact that during short-term periods, shares are subject to higher volatility than bonds. At the same time, for extended periods of investment there is absolutely different situation - standard deviation of yield of shares is lower than with the bonds. Herewith, mathematic expectation of the rate of return per shares and bonds under the extension of the period under study is changed insignificantly, which is well seen in Figure 10. It may be noted that it is always more on shares than on bonds.

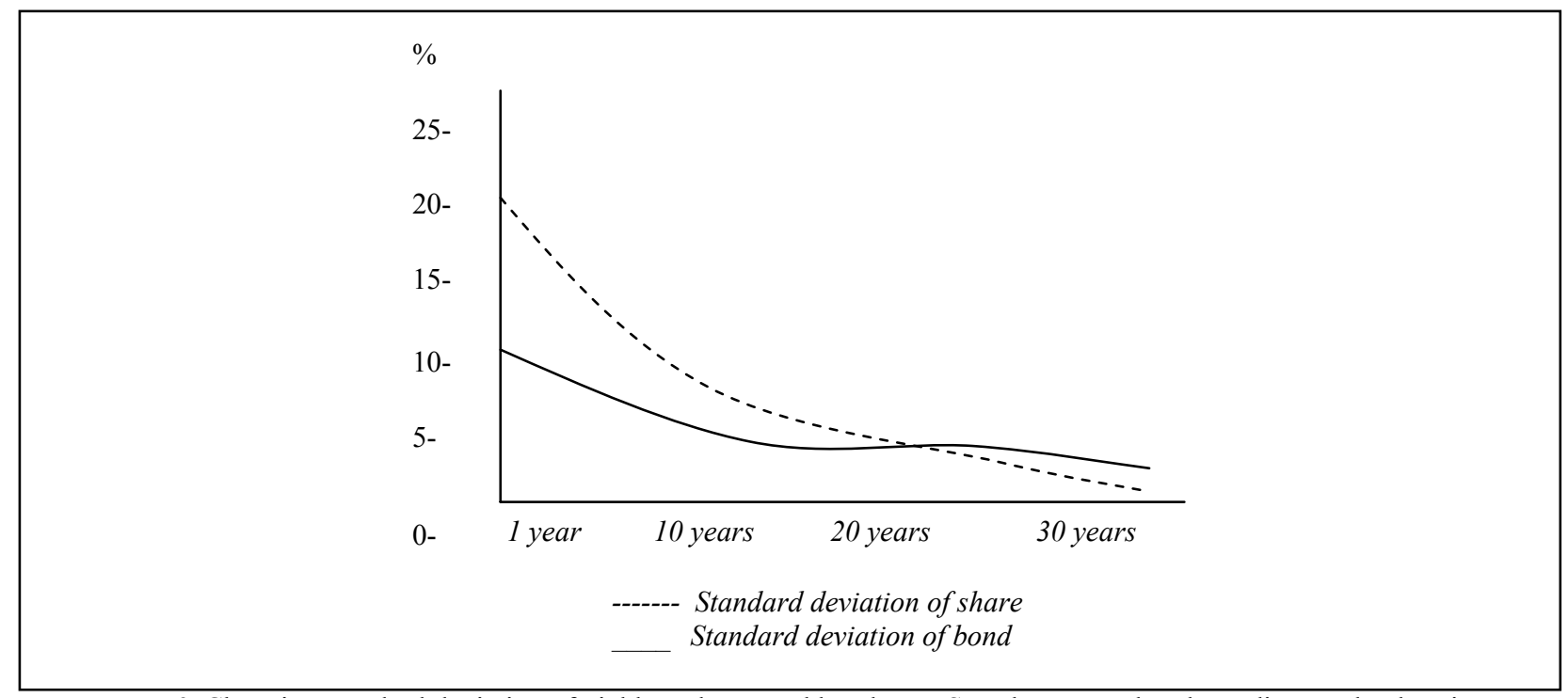

Figure 9. Changing standard deviation of yield on shares and bonds at US exchange market depending on the duration of investments. Source: Sharpe (1970).

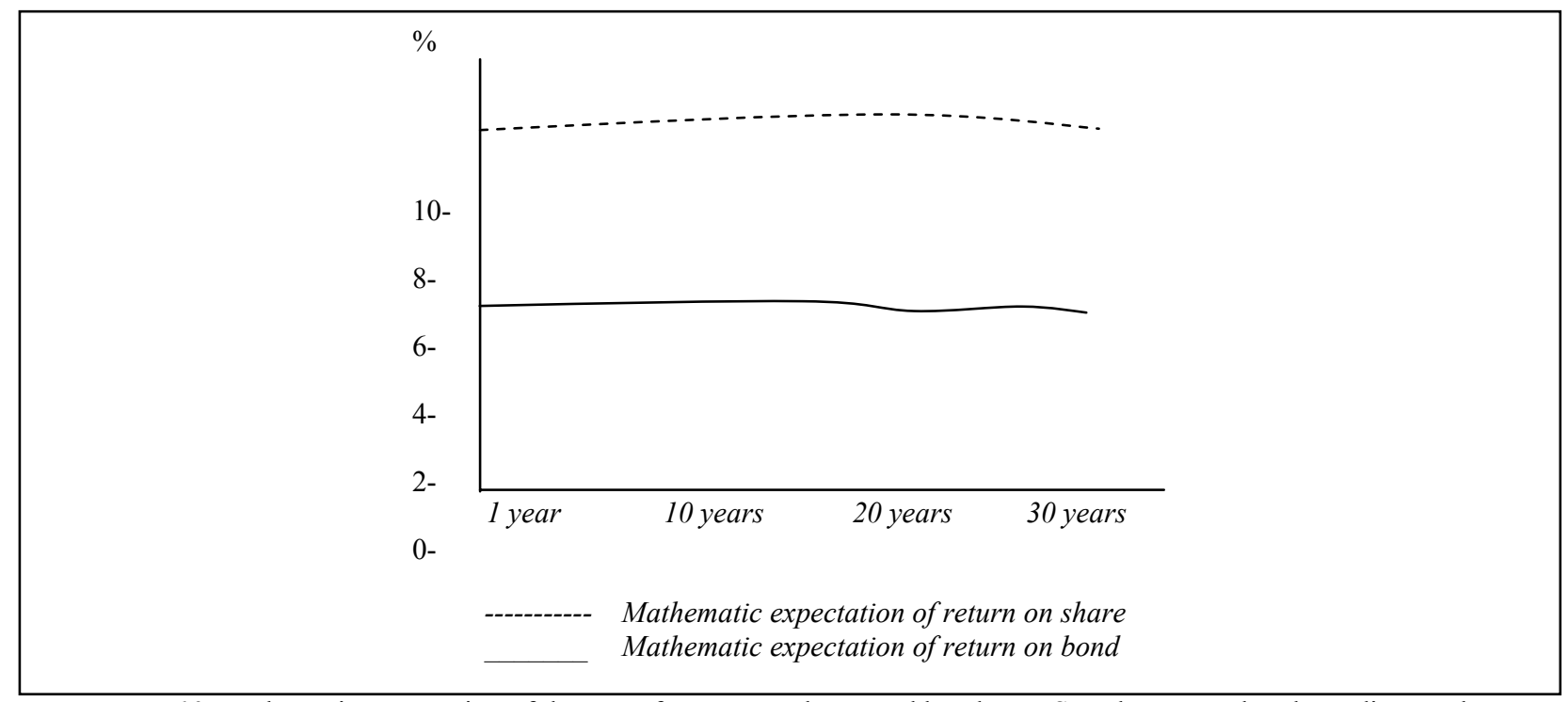

Figure 10. Mathematic expectation of the rate of return per shares and bonds at US exchange market depending on the duration of investments. Source: Sharpe (1970). 
This brings us to a conclusion that increasing terms of investment proportionally changes correlation of risk and yield on shares and bonds. Consequently, under the extended periods of investment the shares appear to be more favorable instruments.

\section{Evaluation of Investment Efficiency}

Evaluation of efficiency investment of the resources at the exchange market is provided through correlation of risk and yield. The most distributed indicator characterizing correlation "risk-rate of return" is Sharp's ratio, which shows the return made by the asset per unit of risk. The higher value the ratio has on the reviewed asset, the high return the investor will earn for the undertaken risk, herewith, and the asset is of more quality per correlation of the risk and yield. Negative value of Sharp's ratio speaks of the fact that high return would be earned in case of investment in risk-free assets.

Formula of Sharp's ratio is as follows:

$$
S h=\frac{\left(\mu_{i}-r\right)}{\sigma_{i}}
$$

where $\mu_{i}$ is mathematic expectation of asset yield (to be calculated as arithmetic mean); $r$-rate of return of risk-free asset; $\sigma_{i}$-standard deviation.

The numerator of the above formula includes the premium for investment risk, and the denominator = risk level. The indicator of standard deviation used for risk measurement is based on the assumption that spread of the values of the indicators of yield is subject to the legislation of normative distribution.

Comparing shares and bonds in view of the risk coverage by the premium in the profitableness also speaks of the fact that increasing the terms of investment influences significantly upon the correlation of return and risk. When analyzing the dynamic of Sharp's ratio under the extended terms of investment (Figure 11), we may note that the shares start prevailing the bonds already with the duration of investment of one year. In case of extended increasing of the terms of investments, shares look clearly much more favorable financial instrument, than the bonds.

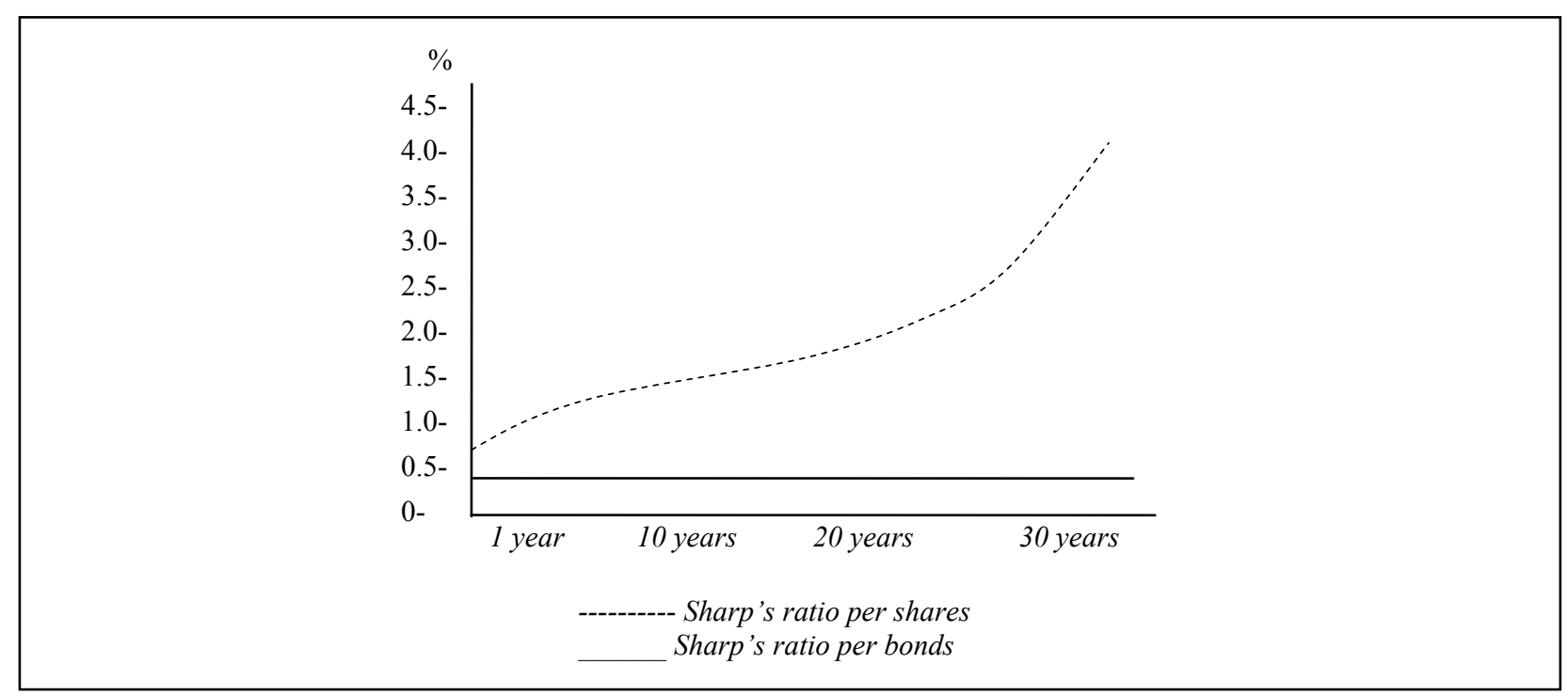

Figure 11. Changing Sharp ratio per shares and bonds at US exchange market, depending on the investment duration. Source: Sharpe (1970). 
Carrying out analysis of correlation of risk and rate of return of financial instruments at the example of US exchange market shows clearly that extension of the terms of investment significantly impacts the evaluation of investment attractively of the financial instruments, grounding investment strategy and selection of the objects of investment. The process of analysis covered sufficiently long historic period of functioning US exchange market, including crash of exchange market in 1929, lasting further Great Depression for several year, further falls and rises of securities, and current economic crisis. Notwithstanding the above, the performed analysis shows that at long time interval, the strategy of passive investment (buy and hold) into the shares justifies itself completely. At the time period of 20 and more years, the shares will give rise not only large return compared with the bonds, but also are imposed to less market.

Thus, surveying correlation of the risk and return at the developed equity markets, US market falls within, demonstrates preemption of the share as investment instrument under long-term investment. The emerging markets are characterized by higher instability and high volatility. Verification of the hypothesis of changing co-relation of the risk and return of the shares and bonds draw a lot of interest. If analyzing efficiency of investment into the shares per RTS index from the beginning of its calculation, time interval is increased to 14 years, allowing carrying out more detailed analysis and review changes in Sharp's ratio for longer investment periods. This analysis period is quite interesting, as it includes the crisis of 1998, when RTS index fell from 550 points to 38 , i.e., 15-times; this was followed by the recovery of the market and growth of the index to the level of 2,488 in 2008, after which sharp fall of the index in relation with the current crisis to the level of 498 and gradual growth of the exchange market.

Increasing reviewed period allowed evaluation of the risk and the yield of investments in the shares for longer periods of time: 1, 6, 1, 2, 24, 36, 48, and 60 months (Figure 12).

According to Figure 12, in case of increasing the terms of investment, the schedule of Sharp's ratio, built on the basis of the market data of shares in Russia, starting from the period of investment, extending 12 months, has sustainable trend for growth and in case of investment for the term of 60 months, the ratio goes close to the unit. We may expect that this level represents the boundary one, under which the efficiency of investment into the shares and bonds are equaled according to Sharp's ratio.

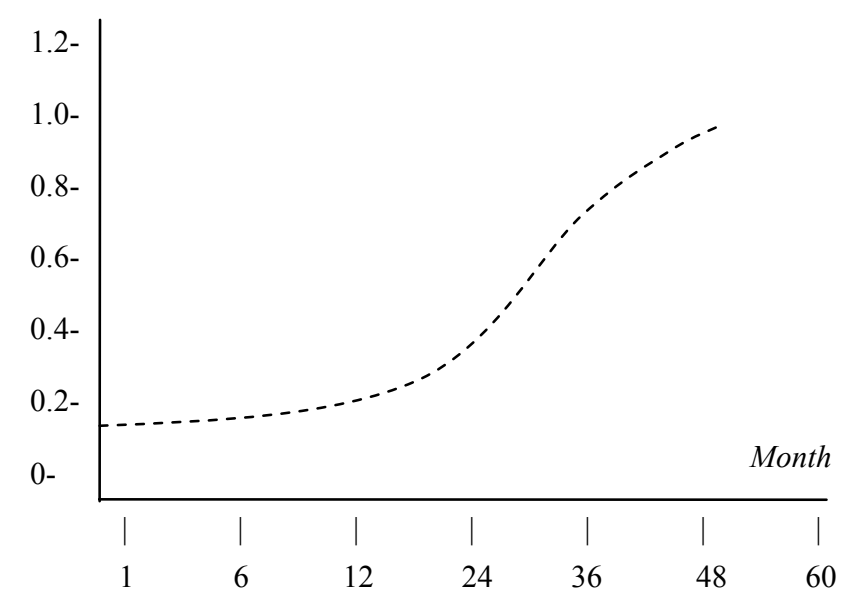

Figure 12. Sharp's ratio per shares, depending on the duration of investment for Russian exchange market, 1995-2009. Source: Sharpe (1970). 
Similar situation is observed with the dynamics of changing Sharp's ratio on shares and bonds during the period of recovery and stable development of Russian market after the crisis of 1998 (the period from 2002 through 2008). Modern stage of development of Russian exchange market will particularly repeat market development after the crisis 1998. After sharp growth of the share market in 2009, when the market plaid half of its fall, further growth will be slow with small corrections. Due to this, it is interesting to review changes risk and return of shares and bonds at different time intervals during the period of recovering the market.

Figure 13 represents changes of Sharp's ratio for the shares and bonds, depending on the duration of investment during the period of sustainable development of the exchange market from January 1, 2002 through June 1, 2008. Sharp ratio chart demonstrates that under the investment terms of 12 months, investments into the shares are compared with the investments into the bonds upon coverage of the risk premium in the yield. In case of further increasing of the investment duration, the shares have the best indicators of premium, in the yield on the risk unit.

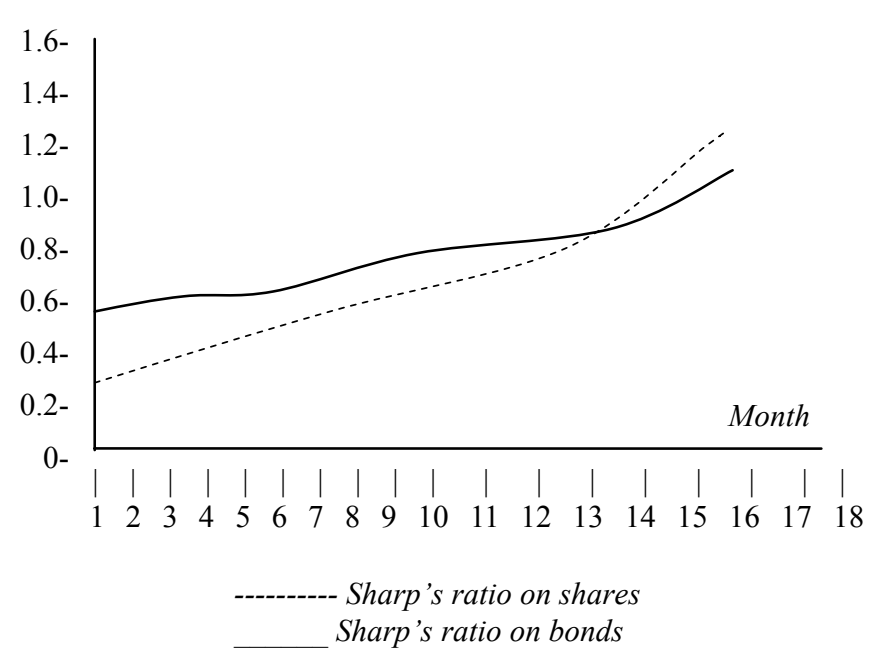

Figure 13. Sharp's ratio for the shares and bonds, depending on the duration of investment during the period of stable development of Russian exchange market. Source: Sharpe (1970).

Results of performed surveys show that Sharp's ratio on bonds seldom reaches a unit. For example, at US market, with the investment term of 30 years, this ratio on the bonds is always less than a unit. Analysis at the Russia market evidences that under the favorable economic conditions, Sharp's ratio on the index Rux-Cbonds in case of investments for the term exceeding a year, lightly exceed a unit. However, Sharp's ratio on shares under the similar conditions, overcome the bonds and enclose 1.5.

In this regards, we may expect that in course of leaving the crisis, the Sharp's ratio on shares will be increased in higher rates, than on the bonds, and at the long-term time horizon, risk covering of the premium in the yield on the shares will exceed similar indicator for the bonds.

\section{Conclusion}

Based on the performed researches, it was identified that there is clearly identified relation between the risk and return of the assets and time horizon of investment. Extending the terms of investment positively influence upon the correlation of return and risk. High volatility of exchange market in the short-term period is 
conditioned with ineffectiveness of the markets, existence of information noise, games of the speculators, and some other factors, acting during short term period. In the long-term perspective, the exchange markets reflect state of the affairs under the real sector of economy. In regards with the fact that the economy is being developed through the evolution way and, notwithstanding cycled falls and rises, have the trend of growth, investments into the shares on the long-term time horizon always have positive results. The results of investigation, received at Russian exchange market, coincide with the results made by R. Gibson, K. Harvey, F. Nardari and J. Skruggs for the evaluation of the markets and returns on assets at the developed equity market.

Share volatility is the negative factor for short-term investments. During long-term period, the volatility has positive accent, as it represents the basis for higher return. In this regards, the shares are much profitable assets for investment for long-term period. This proves that more risky assets in short-term period may correspond to the instruments for conservative investor, investing his/her sources for long-term period.

Possibilities in CAPM model maximally simplify a situation on investment market towards financial sources: Every investor has one and the same information and similarly evaluates changes on financial markets. Capital markets themselves are effective. This enables to find out further problems. How should an investor make investments? What will happen to financial resources if every investor acts with the same manners? In other words we try to answer the question if all investors know G. Markovits' theory and formulate only optimal portfolios, which support maximally possible profit on maximally possible profit on minimally predicted markets and if financial markets are effective, then what kind of effect will investors' joint action make on financial sources market? While researching every investor's joint action it can be revealed balanced relation between predicted profit and securities risk.

We also want to highlight one circumstance. Possibilities in CAP Model maximally simplify the situation on investments market towards financial sources: Each investor has one and the same information and evaluates changes on financial markets in the same way. All these things make it possible to find out the following problems: How should an individual investor make investments? What will happen to financial resources if all the investors act in the same manners?

In other words we try again to answer the question. All investors know Markovits' theory and create only optimal portfolios, they support maximally possible markets, financial markets are effective as well, but what kind of influence will investors' joint action make on financial sources market? On the very market it can be revealed balanced relation between possible income and securities risk.

CAPM model possibilities make it possible to make first prognosis of financial prices. For evaluating deep analysis it is necessary to consider that CAPM is a sample model, which is based on preliminary conditions. So we consider that it should be evaluated how precisely the mentioned model matches to reality, but carrying out such control is not so easy.

Numerous researches which were carried out to evaluate CAPM model precision gave us opposite results. But this topic is beyond our article and is the topic of further research.

\section{References}

Ang, A., Hordick, R., Xing, Y., \& Zhang, X. (2004). The cross-section of volatility and returns. Working paper. New York: Columbia Business School.

Burberis, N., Huang, M., \& Santos, T. (1999). The center for research in security prices. Working paper. Chicago: University of Chicago, Graduate School of Business.

Gibson, R. (2000). Asset allocation: Ballansing risk. New York: McGraw-Hill. 
Ibbotson, R., \& Chen, P. (2002). Stosk market returns in the long run: Participating in the real economy. Working paper. New Haven: Yale School of Management.

Lo, A. (2002). The statistics of Sharpe ration. Financial Analysts Journal, 58(4), 36-50.

Lucas, A., \& Klaasen, P. (1998). Extreme returns, downside risk, and optimal asset allocation. The Journal of Portfolio Management, 25(1), 71-79.

Nardari, F., \& Scruggs, J. (2005). Why does stock market volatility change over time? A time-varying variance decomposition for stick returns. Working paper. Tempe: Arizona State University.

Pezier, J., \& White, A. (2006). The relative merits of investable hedge fund indices and of funds of hedge funds in optimal passive portfolios. Working paper. Reading: School of Business Reading University.

Qoqiauri, L. (2010). Investments practice. Tbilisi: Technical University of Georgia.

Qoqiauri, L. (2013). Financial market. In Fundamental and technical analysis of security market (pp. 558-571). Tbilisi: Thechnica University of Georgia.

Qoqiauri, L. (2015). Financial crisis and adventure of the Georgian Lari. New York: Nova Publishers.

Robertson, D., \& Wright, S. (1998). The gold news and the bad news about long-run stock market returns. Working paper. Cambridge: University of Cambridge.

Sharpe, W. (1970). Portfolio theory and capital markets. New York: McGraw-Hill.

Sharpe, W., Alexander, G., \& Beili, G. (1995). Investments. New Jersey: Prentice Hall, Inc. A Simon and Schuster Company Englawood Cliffs.

Sortino, F. A., \& Van Der Meer, R. (1991). Downside risk. The Journal of Portfolio Management, 17(4), $27-31$. 